6-15-2014

\title{
A New Liquid Chromatography/Tandem Mass Spectrometry Method for Quantification of Gangliosides in Human Plasma
}

\author{
Qianyang Huang \\ Cleveland State University \\ Xiang Zhou \\ Cleveland State University, x.zhou34@csuohio.edu \\ Danting Liu \\ Cleveland State University \\ Baozhong Xin \\ Center for Special Needs Children \\ Karen Cechner \\ Center for Special Needs Children
}

See next page for additional authors

Follow this and additional works at: https://engagedscholarship.csuohio.edu/scichem_facpub

Part of the Chemistry Commons

How does access to this work benefit you? Let us know!

\section{Recommended Citation}

Huang, Qianyang; Zhou, Xiang; Liu, Danting; Xin, Baozhong; Cechner, Karen; Wang, Heng; and Zhou, Aimin, "A New Liquid Chromatography/Tandem Mass Spectrometry Method for Quantification of Gangliosides in Human Plasma" (2014). Chemistry Faculty Publications. 375.

https://engagedscholarship.csuohio.edu/scichem_facpub/375

This Article is brought to you for free and open access by the Chemistry Department at EngagedScholarship@CSU. It has been accepted for inclusion in Chemistry Faculty Publications by an authorized administrator of EngagedScholarship@CSU. For more information, please contact library.es@csuohio.edu. 
Authors

Qianyang Huang, Xiang Zhou, Danting Liu, Baozhong Xin, Karen Cechner, Heng Wang, and Aimin Zhou

This article is available at EngagedScholarship@CSU: https://engagedscholarship.csuohio.edu/scichem_facpub/375 


\title{
A new liquid chromatography/tandem mass spectrometry method for quantification of gangliosides in human plasma
}

\author{
Qianyang Huang . Xiang Zhou . Danting Liu . Baozhong Xin . Karen Cechner . Heng Wang \\ Aimin Zhou
}

\begin{abstract}
Gangliosides are a subgroup of glycosphingolipids that present abundantly in the central nervous system [1]. They generally con sist of a mono or polysialic acid containing hydrophilic oligosac charide moiety linked with a hydrophobic ceramide portion that comprises a sphingosine backbone and a fatty acid chain with a variable number of carbons. Such compounds are predominately localized at the cellular membrane of neuronal and glial cells with their ceramide portion embedded inward into the outer leaflet of the lipid bilayer and the oligosaccharide moiety protruding out ward into the extracellular matrix [2]. To date, more than 180 gan glioside species with characteristic carbohydrate moieties have been identified in vertebrates. In addition to disparate linking arrangements among various monosaccharide units in carbohy
\end{abstract}

drate moiety, each species possesses multiple components with the ceramide portion encompassing an alterable chain length of a fatty acid, which implies the great structural heterogeneity of such molecules [3] (corresponding classifications and nomenclatures are shown in Fig. 1). The structural diversity empowers ganglia sides with the versatility for biologically functioning as modulators of signaling receptors in the regulation of various cellular events such as neurotrophy and neurotransmission by physiologically interacting with regulatory proteins in the nervous system [4].

The exact physiological role of gangliosides in the brain is not fully understood yet, but they are believed to be functioning in the regulation of receptor mediated cell signaling pathways, espe cially in cell differentiation, proliferation, and death [5 8]. Such functions turn out to be typically serving as integral components of cell surface microdomains [9] or lipid rafts [10] along with pro teins, sphingomyelins, and cholesterol in administering signal events affecting neural development and contributing to the pathogenesis of numerous clinical diseases and disorders, including GM3 synthase deficiency (GSD) [11 13], Tay Sachs 


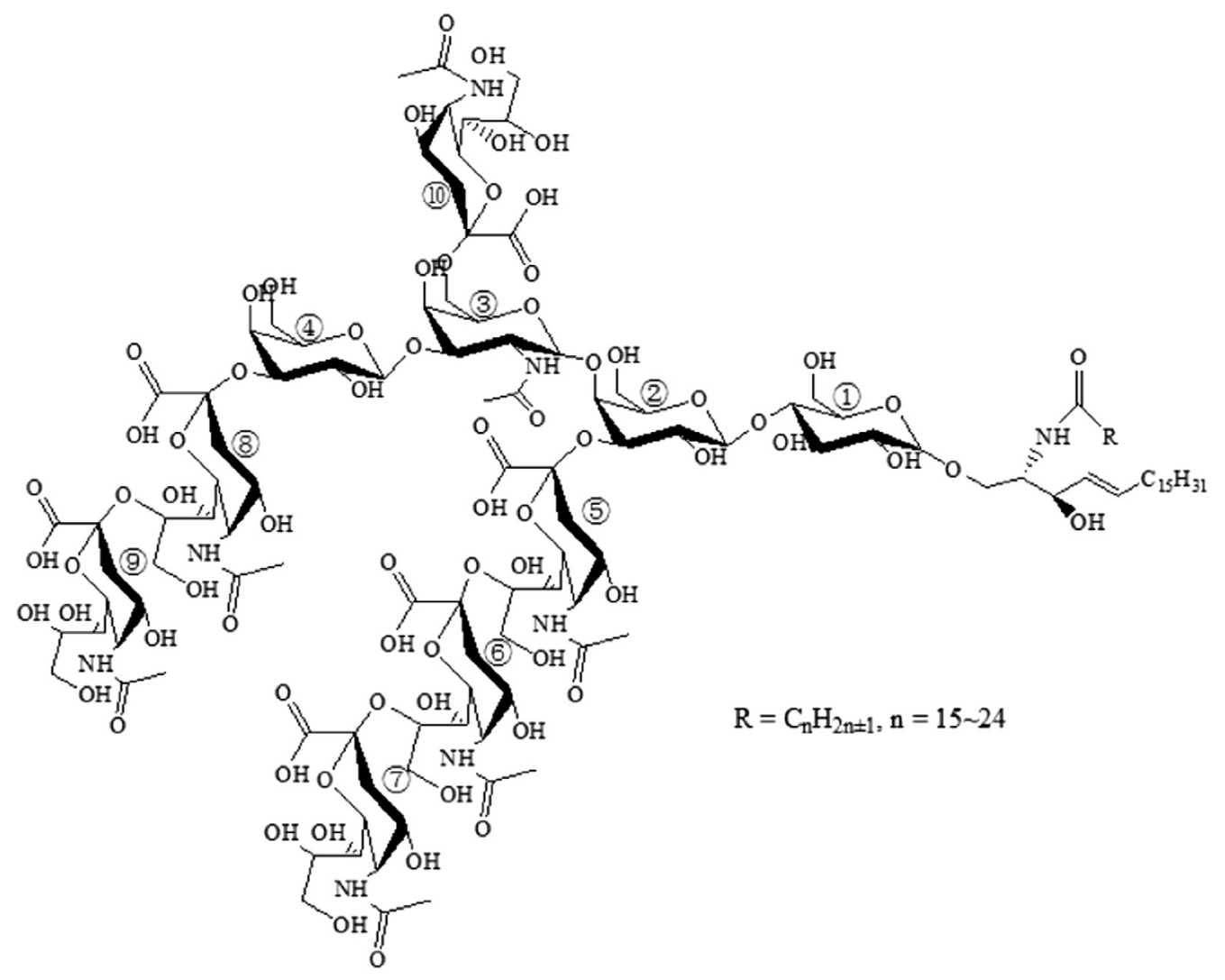

\begin{tabular}{|c|c|c|c|}
\hline GM3 & (1)(2)(5) & GT1a & (1)(2)(3)(4)(5)(8)(9) \\
\hline GM2 & (1)(2)(3)(5) & GT1b & (1)(2)(3)(4)(5)(6)(8) \\
\hline GM1a & (1)(2)(3)(4)(5) & GT1c & (1)(2)(3)(4)(5)(6)(7) \\
\hline GM1b & (1)(2)(3)(4)(8) & GT1 $\alpha$ & (1)(2)(3)(4)(5)(6) \\
\hline GD3 & (1)(2)(5)(6) & GQ1 $\alpha$ & (1)(2)(3)(4)(5)(6)(8)(10) \\
\hline GD2 & (1)(2)(3)(5)(6) & GQ1b & (1)(2)(3)(4)(5)(6)(9) \\
\hline GD1a & (1)(2)(3)(4)(5)(8) & GQ1c & (1)(2)(3)(4)(5)(6)(7)(8) \\
\hline GD1b & (1)(2)(3)(4)(5)(6) & & \\
\hline
\end{tabular}

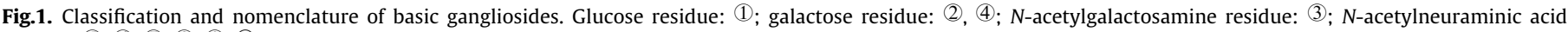
residue: (5), (6), (7), (8), (9), (10).

disease [14,15], and Sandhoff disease [16 18]. GM3 synthase defi ciency is a neurological disorder recently identified among the Amish people in the United States caused by mutation of the GMs synthase gene, resulting in the absence of GM3 and its down stream metabolites. The clinical manifestation of these patients is similar to intractable seizures with profound mental and physical retardation [11]. During recent years, studies have illustrated aberrant ganglioside profiles in neurodegenerative syndromes, implying their potential contribution to the development or progression of these chronic and incurable neurodegenerative disorders such as Parkinson disease $[19,20]$ and Alzheimer disease [21].

During past decades, measurement or profiling of gangliosides in animal tissues, cultured cells, or cerebrospinal fluid has been reported using thin layer chromatography coupled with densito metric detection [22] or immunochemical detection [23], high performance liquid chromatography (HPLC) ${ }^{1}[24,25]$, supercritical fluid chromatography [26], and enzyme linked immunosorbent assay [27]. These methods are subjected to limitations such as large sample requirement, laborious sample preparation, time consuming measurement, and insufficient sensitivity and specificity. Recently, the advent of mass spectrometry (MS) has given rise to the excellent quantitative analysis featured by promising sensitivity and resolution for the determination of gangliosides. $\mathrm{Gu}$ and coworkers 
established a method for simultaneous quantification of GM1 and GM2 gangliosides in human cerebrospinal fluid using reverse phase liquid chromatography (LC)/MS [28]. Sørensen reported an LC approach interfaced with tandem mass spectrometry (MS/MS) for the quantification of gangliosides GD3 and GM3 in bovine milk and infant formula [29].

In the current work, we have developed and validated an ultra performance liquid chromatography (UPLC)/MS/MS method for the measurement of four common ganglioside species GM2, GM3, GD2, and GD3 in human plasma. This assay employs a simple pro tein precipitation strategy for sample extraction, UPLC for chro matographic separation, and MS/MS in the multiple reaction monitoring (MRM) mode for detection to achieve high sensitivity and specificity for rapid analysis. We successfully applied this method to measure the four species of gangliosides in human plasma.

\section{Materials and methods}

\section{Materials}

Ganglioside standards GM3 and GD3 were purchased from Avantilipids (Alabaster, AL, USA). GM2 and GD2 ganglioside stan dards were obtained from EMD Chemicals (Billerica, MA, USA) and Enzo Life Sciences (Farmingdale, NY, USA), respectively. The internal standard (IS) $N$ omega CD3 octadecanoyl monosialogan glioside GM3 (GM3 D3) was purchased from Matreya (Pleasant Gap, PA, USA). HPLC grade methanol and isopropanol were obtained from EMD Millipore (Billerica, MA, USA). Deionized water was prepared through the Barnstead Nano PURE Water Purifica tion System (Asheville, NC, USA). Ammonium acetate was obtained from VWR (Bridgeport, NJ, USA)

\section{Human plasma}

The study was approved by the DDC Clinic institutional review board (Middlefield, OH, USA), and written informed consent was obtained from patient legal guardians. Clinical information was collected when the patients received medical services at the DDC Clinic. Human plasma samples were stored at $-20{ }^{\circ} \mathrm{C}$ before analysis.

\section{Stock and work solutions}

Stock solutions of GM2, GM3, GD2, GD3, and IS GM3 D3 were prepared by dissolving the original materials individually into $80 \%$ methanol to obtain a concentration of $0.25 \mathrm{mg} / \mathrm{ml}$ for each and were stored at $-20{ }^{\circ} \mathrm{C}$ before use. Three work solutions were prepared in $80 \%$ methanol from the stock solutions to obtain gan glioside concentrations as follows: $3,13.6,0.125$, and $2 \mu \mathrm{g} / \mathrm{ml}$ (WS QC); 4.5, 20.4, 0.125, and $3 \mu \mathrm{g} / \mathrm{ml}$ (WS 1); and 18, 81.6, 0.5, and $12 \mu \mathrm{g} / \mathrm{ml}$ (WS 2) for GM2, GM3, GD2, and GD3, respectively. The IS stock solution also served as its work solution, named as WS IS. These work solutions were used for preparation of spiked plasma samples as below.

\section{Plasma sample preparation}

For method validation, known concentration samples were pre pared by spiking ganglioside standards into the analyte free plasma from patients with GM3 synthase deficiency. In brief, $30 \mu \mathrm{l}$ of ana lyte free plasma was transferred into each of three $0.6 \mathrm{ml}$ centrifuge vials (a, b, and c), followed by individual addition of $10 \mu \mathrm{l}$ of WS QC to obtain the plasma concentrations of $1.00,4.53,0.04$, and $0.67 \mu \mathrm{g} / \mathrm{ml}$ for GM2, GM3, GD2, and GD3, respectively. Thereafter,
$10 \mu \mathrm{l}$ of $80 \%$ methanol, WS 1 , and WS 2 were spiked into the vials a, b, and c, respectively. Afterward, $10 \mu \mathrm{l}$ of WS IS was spiked into each of the three samples, and this set of samples was named as spiked analyte free plasma (SAP), standard addition 1 (SA 1), and standard addition 2 (SA 2), respectively.

For measurement of the gangliosides in unknown plasma sam ples from normal human subjects, a similar procedure as described above was followed except that WS QC was not added. The three samples in each set were named as unknown plasma sample (UPS), SA 1, and SA 2, respectively. All of the plasma samples were extracted as described below prior to LC/MS/MS analysis.

\section{Sample extraction}

Following the plasma sample preparation, $240 \mu$ l of methanol was added into each of them, followed by vigorous vortexing. Then, the spiked samples were subjected to centrifugation at $14,000 \mathrm{~g}$ for $15 \mathrm{~min}$ at $4{ }^{\circ} \mathrm{C}$ for protein precipitation. The superna tants were transferred into autosampler vials with micro inserts for LC/MS analysis.

\section{LC/MS instrumentation}

The UPLC system was composed of a DGU $20 \mathrm{~A}_{3 \mathrm{R}}$ degasser, two LC 30AD pumps, an SIL 30AC autosampler, a CTO 10A column oven, and a CBM 20A system controller from Shimadzu (Columbia, MD, USA). The UPLC system was interfaced to a Qtrap 5500 mass spectrometer equipped with an electrospray ionization source and a built in Valco switch valve from AB SCIEX (Framingham, MA, USA). The MRM mode was used for quantitation. Data acquisi tion and chromatographic peak integration were conducted using the Analysis 1.6.1 software package from AB SCIEX.

\section{LC/MS/MS procedure}

After extraction, $30 \mu \mathrm{l}$ of each sample was injected onto a Kine tex C18 UPLC column $(1.7 \mu \mathrm{m}, 50 \times 2.1 \mathrm{~mm}$; Phenomenex, Tor rance, CA, USA) guarded with a C18 Security Cartridge. The mobile phase was a mixture of $2 \%$ methanol plus $5 \mathrm{mM}$ ammonium acetate $(A)$ and methanol isopropanol (1:1) plus $5 \mathrm{mM}$ ammo nium acetate (B) using the gradient program shown in Table 1. The LC flow at $0.3 \mathrm{ml} / \mathrm{min}$ was introduced to the waste within the first $2 \mathrm{~min}$ and then switched to the mass spectrometer between 2.1 and $9.0 \mathrm{~min}$ while all of the monitored ganglioside components were gradually eluted out. Afterward, the LC flow at $0.6 \mathrm{ml} / \mathrm{min}$ was directed to the waste again, during the column was cleaned up and reequilibrated for the next run. The column temperature was constantly controlled at $35^{\circ} \mathrm{C}$ during the analysis.

Table 1

Optimized UPLC conditions for the separation of ganglioside components.

\begin{tabular}{lllll}
\hline Time $(\mathrm{min})$ & $\mathrm{B} \%$ & Flow rate $(\mathrm{ml} / \mathrm{min})$ & Stage & Valco switch valve \\
\hline 0 & 30 & 0.3 & Elution & To waste \\
1 & 30 & & & \\
2 & 70 & & & To MS \\
2.01 & 70 & & Cleanup & To waste \\
9 & 95 & & \\
9.01 & 95 & 0.6 & Equilibration & \\
15.5 & 95 & & & \\
15.51 & 30 & & & \\
19.5 & 30 & & & \\
19.51 & 30 & 0.3 & & \\
20.0 & 30 & & &
\end{tabular}

Note: A: $2 \%$ methanol $+5 \mathrm{mM}$ ammonium acetate; B: methanol-isopropanol $(1: 1)+5 \mathrm{mM}$ ammonium acetate. 
Calibration curve

Quantitation of the gangliosides in the SAP and UPS was imple mented using standard addition calibration based on three levels: one to be measured sample with nil addition and two standard addition calibrators (SA 1 and SA 2). For each measured ganglio side specimen, the total peak area (TPA) was obtained by summing the individual peak area from every MRM transition channel in the corresponding sample from a single injection.

The three level calibration curve for each ganglioside sample was then established by plotting its normalized TPA by the IS as the $y$ axis versus the plasma concentration of standard addition as the $x$ axis. The linear regression with a weighting factor of $1 /$ $y^{2}$ was employed. The calculation of each ganglioside plasma con centration in a sample was conducted using the corresponding equation obtained from the regression line as its intercept with the $x$ axis through extrapolation. Exemplified standard addition calibration curves for each of the four measured gangliosides from the measurement of healthy individuals are shown in Fig. 2.

\section{Results and discussion}

Product ion mass spectra

The representative product ion mass spectra of D18:1 20:0 gan glioside components for the four ganglioside species from added standards are shown in Fig. 3. Apparently, fragmentation pattern relevance can be observed within GM series and GD series, includ ing the common product ions $m / z 274$ and 292 for GM series and $\mathrm{m} / z 290$ and 581 for GD series. Owing to their relatively greater molecular masses, the singly charged ions of gangliosides are beyond the detection ranges of our mass spectrometer and many other commercially available triple quadruple instruments. There fore, the selection of doubly charged precursor ions and their appropriate daughter ions as MRM transition channels was neces sary for quantitation in this assay.

For GD series, two proton donating carboxyl groups are attached to their sialic acid moieties in the carbohydrate portion; the generation of doubly charged ions had been observed to be more favorable in the negative ionization mode than in the positive ionization mode. For GM series that contain only one proton donating carboxyl group, the signal responses from doubly charged precursor ions were practically undetectable in the negative ioni zation mode under various conditions we studied during the method development. Because the positive mode was found to be more effective in yielding doubly charged precursor ions from GM2 and GM3, positive ionization was selected for determining GM series.

After evaluating different pairs of precursor $\rightarrow$ product ions for quantitation, it was revealed that the following MRM transitions provided the optimal sensitivity and selectivity: $\left[\mathrm{GM} 2+2 \mathrm{H}^{+}\right]^{2+} \rightarrow$ 204, $\left[\mathrm{GM} 3+2 \mathrm{H}^{+}\right]^{2+} \rightarrow 274, \quad\left[\mathrm{GD} 2-2 \mathrm{H}^{+}\right]^{2-} \rightarrow 290$, and [GD3 $\left.2 \mathrm{H}^{+}\right]^{2-} \rightarrow 290$. The fragmentation mechanisms from the precursor to the daughter ions are interpreted and elaborated in Fig. 4.

\section{Selection of MRM transitions}

As shown in Fig 1, each ganglioside species includes multiple components that share the same oligosaccharide moiety but differ
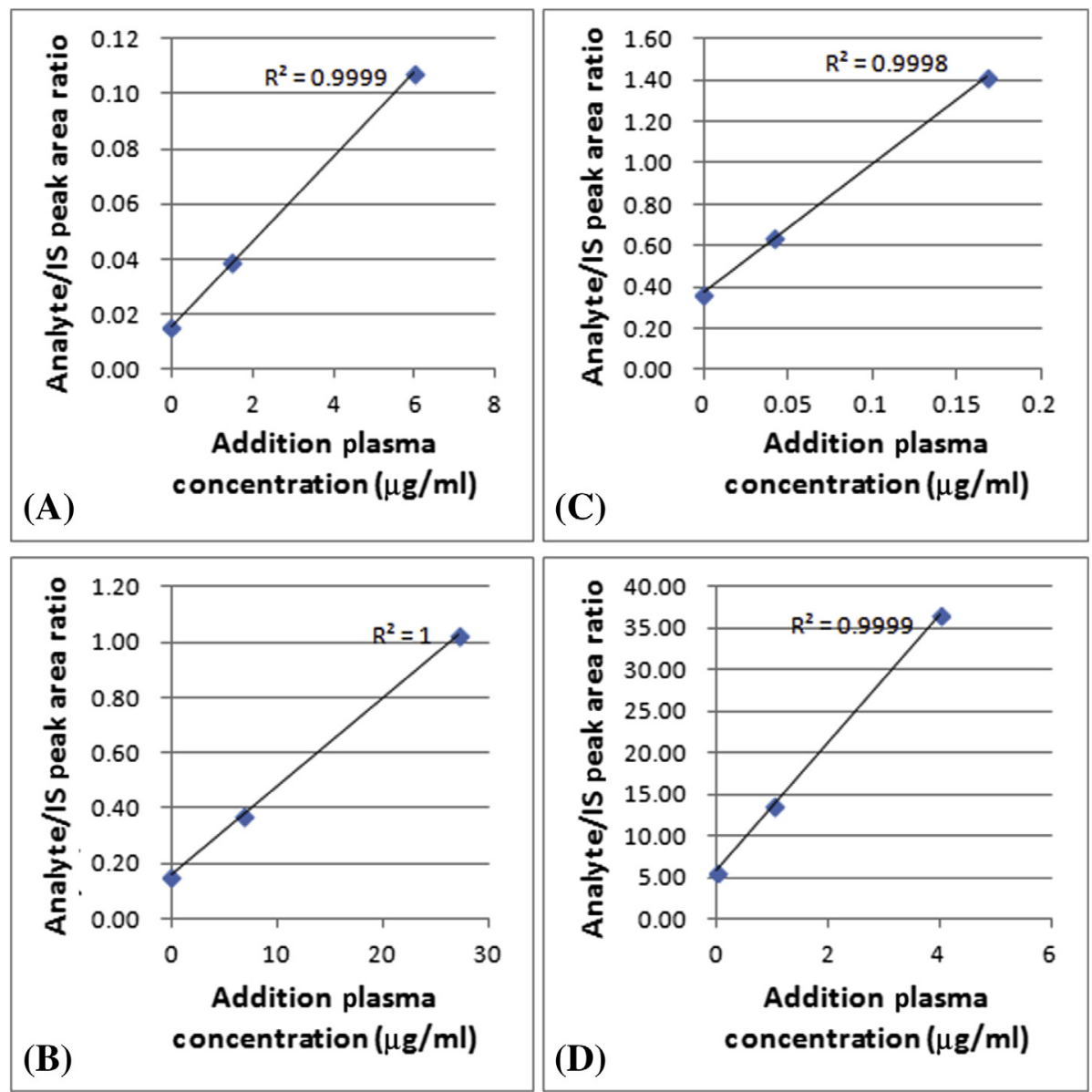

Fig.2. Exemplified calibration curves for GM2 (A), GM3 (B), GD2 (C), and GD3 (D) from the measurement of a healthy subject. 

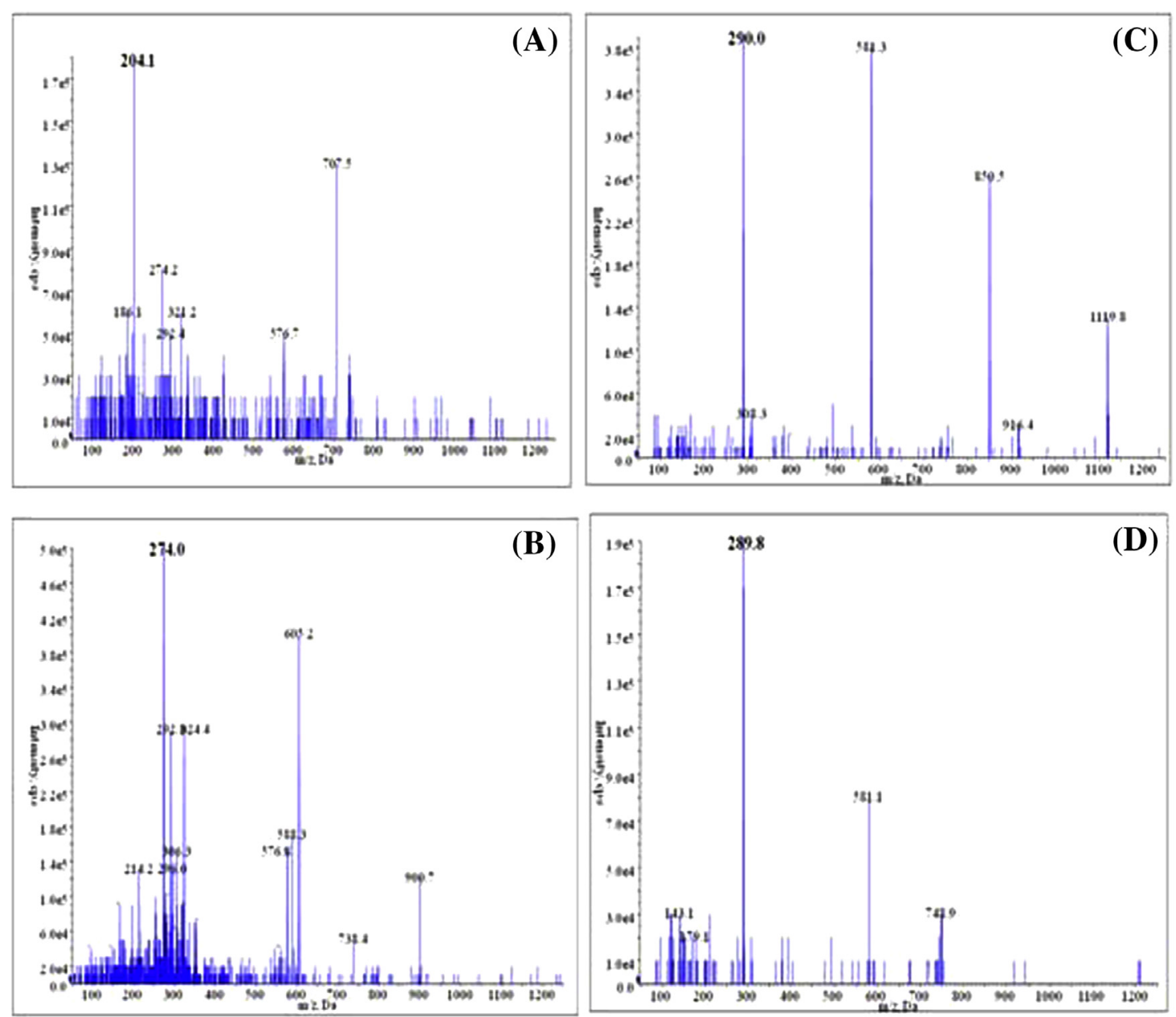

Fig.3. Product ion (MS/MS) spectra for D18:1-20:0 GM2 (A), GM3 (B), GD2 (C), and GD3 (D) gangliosides.

in fatty acid chain length within their ceramide portion. For accu rate quantitation, all of the major ganglioside components from each ganglioside species with appreciable abundance in the plasma and commercial standards need to be detected in the analysis. Therefore, we first carried out a screening study on predominant ganglioside components of individual ganglioside species in both normal human plasma and commercial standards using the pre dicted MRM channels through LC/MS/MS analysis. The selected MRM transitions corresponding to all of the significant ganglioside components observed by such analysis for the quantitation of the four ganglioside species are listed in Table 2. In addition to the quantitation MRM channels, quality assurance MRM channels with transitions from their precursor ions to $m / z$ 274, 292, 290, and 290 were also employed for GM2, GM3, GD2, and GD3, respectively. Our experiments showed that the response ratio for each pair of MRM channels was practically constant in the standard spiked sol vent and unknown plasma extracts, confirming the identity of the monitored components.

\section{HPLC conditions}

In view of multiple MRM transitions having been exploited to monitor each of the four ganglioside species, a sufficient chromato graphic separation between ganglioside molecules and plasma interferences is essential to eliminate the potential ionization sup pression influence from the matrix for the acquisition of high qual ity quantification during the analysis. Based on our preliminary studies during the method development, a C18 reverse phase UPLC column was found to provide the best resolution for multiple gan glioside components. Under our optimized LC conditions, all of the ganglioside components were eluted out and spread within a retention time window from 3 to $9 \mathrm{~min}$. In general, gangliosides could be strongly retained by the $\mathrm{C} 18$ stationary phase due to the hydrophobic nature of their ceramide portion. We observed that the use of methanol isopropanol $(1: 1)$ as the solvent of mobile phase B could elute the gangliosides from the C18 station ary phase more effectively than the use of methanol only and could lead to shorter chromatographic running time and better peak shapes. The MRM chromatograms for the major components of GM3 ganglioside are shown in Fig. 5.

It is noteworthy that the addition of $5 \mathrm{mM}$ ammonium acetate in the mobile phases considerably reinforced the peak intensities from all MRM channels in both positive and negative ionization modes. This experimental phenomenon can be reasonably ascribed to ammonium acetate's ability to stabilize the $\mathrm{pH}$ at the neutral range, enabling both the proton donating interaction between the ammonium group and gangliosides in the positive mode and the proton accepting interaction between the acetate group and gangliosides in the negative mode to be undertaken for the promo tion of ionizing efficiency during the electrospray ionization. While ammonium formate or formic acid was added into the mobile phases, the responses from positive ionization was enhanced to a certain extent, whereas substantial signal suppression occurred in negative ionization, which was apparently attributable to the 

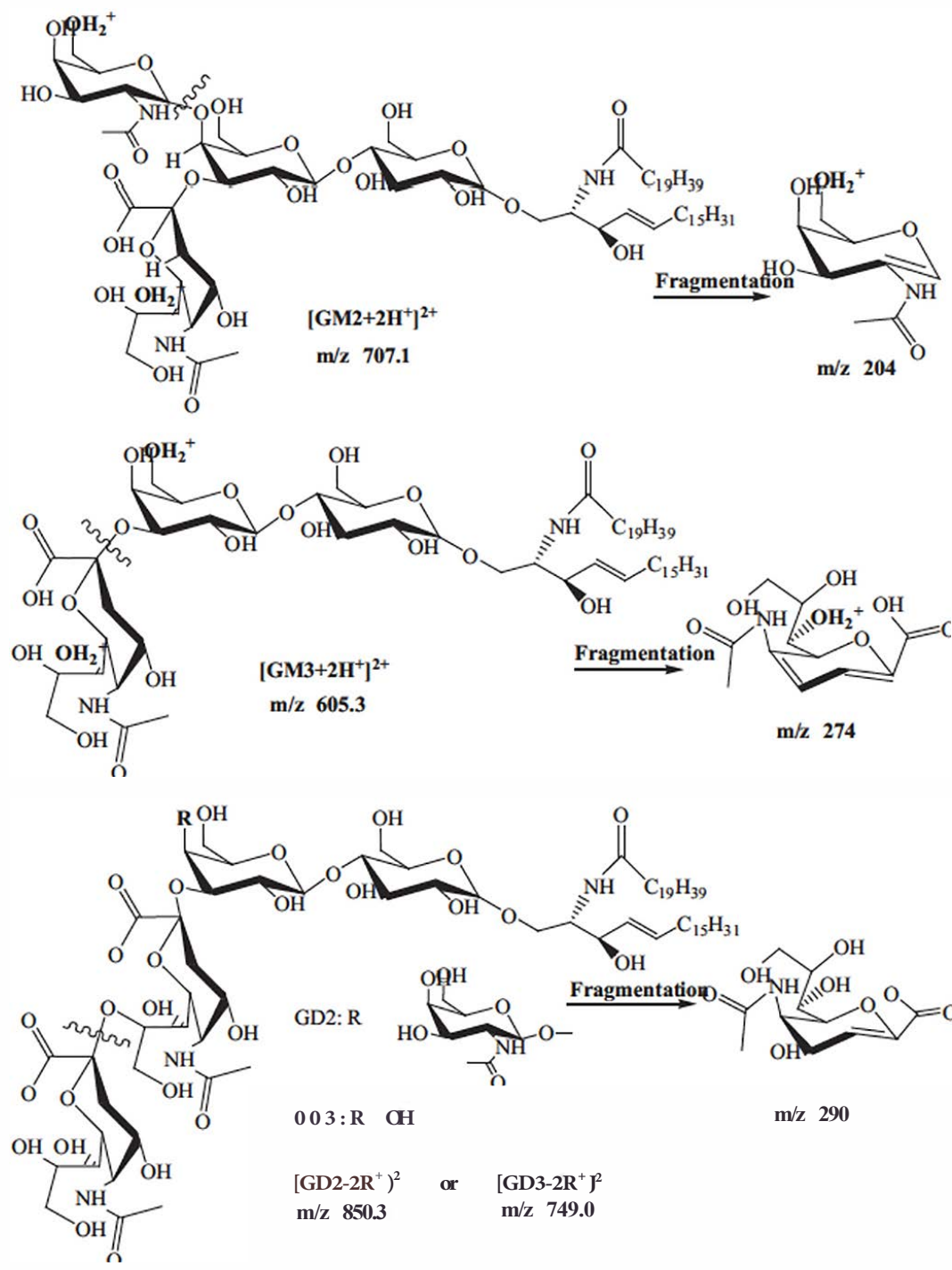

Fig.4. Proposed fragmentation mechanisms for 018:1-20:0 components of GM2, GM3, GD2, and GD3 gangliosides.

intensified proton donating tendency of formic acid and ammo nium formate as compared with ammonium acetate.

\section{Sampleextractionprocedure}

The most commonly used method for the isolation of ganglia sides from biomatrices is a liquid liquid partition strategy, first reported by Svennerholm and Fredman [30] for the treatment of human brain samples, which was used or modified later by other investigators [29,31,32] for extracting gangliosides from milk and other matrices. In brief, the workflow is constructed by the follow ing steps: (i) mixing the biomatrix with chloroform/methanol/ water (4:8:3) by vigorous shaking, (ii) transferring the ganglia side enriched methanol/water upper phase into a new container without disturbing the middle and lower phases, (iii) drying the crude extract with inert gas purging, and (iv) reconstituting the residues with methanol to a certain volume for quantitative anal ysis. To compare the extraction recovery by using our simple pro tein precipitation procedure and the existing extraction method, we performed a series of parallel studies. In these assays, ana lyte free plasmas were spiked with the gangliosides, followed by extraction with two different extraction methods. As expected, our protein precipitation method not only was easy to handle and time saving, but also provided full recovery for all four gangli aside species (Table 3). In contrast, the reported method generated insufficient recovery for GM2 and GM3 gangliosides. According to the literature, protein precipitation from plasma samples was com manly conducted by the addition of 3 to 4 fold methanol or ace tonitrile, followed by high speed centrifugation. However, the widely adopted condition generated unsatisfactory recovery of gangliosides from plasma. Based on modest polarity of ganglia sides from their hydrophilic oligosaccharide moiety and hydropho bic ceramide portion, we attempted to achieve the best extraction recovery through adjustment of the polarity by increasing the por tion of methanol. Nearly $100 \%$ extraction recovery was achieved for all four ganglioside species by the addition of 8 fold methanol into plasma for protein precipitation.

\section{Standardadditioncalibration}

According to U.S. Food and Drug Administration (FDA) guide lines for bioanalytical method validation [33], the same type of matrix as actual samples should be used for the preparation of calibrators and quality controls during the quantitative method development and validation whenever feasible concerning the potential pronounced signal interference imposed by the complex 
Table 2

Selected MFM transitions for quantitation of the four gangtioside species.

\begin{tabular}{|c|c|c|c|c|c|}
\hline \multicolumn{3}{|c|}{ Positive mode } & \multicolumn{3}{|c|}{ Negative mode } \\
\hline Species & Component & $\begin{array}{l}\text { MRM } \\
\text { transition }\end{array}$ & Species & Component & $\begin{array}{l}\text { MRM } \\
\text { transition }\end{array}$ \\
\hline \multirow[t]{6}{*}{ GMR } & 018:1-14:0 & $665.1 / 204$ & $\mathrm{CO} 2$ & 018:1-14:0 & $808.3 / 290$ \\
\hline & 018:1-16:1 & $678.1 / 204$ & & 018:1-16:0 & $822.3 / 290$ \\
\hline & $018: 1-16: 0$ & $679.1 / 204$ & & 018:1-18:1 & $835.3 / 290$ \\
\hline & 018:1-18:1 & $692.1 / 204$ & & 018:1-18:0 & $836.3 / 290$ \\
\hline & $018: 1-18: 0$ & $693.1 / 204$ & & 018:1-19:0 & $843.3 / 290$ \\
\hline & 018:1-20:0 & $707.1 / 204$ & & 018:1-20:0 & $850.3 / 290$ \\
\hline \multirow[t]{17}{*}{ GMB } & 018:1-12:0 & $549.3 / 274$ & & 018:1-21:0 & $857.3 / 290$ \\
\hline & $018: 1-14: 0$ & $563.3 / 274$ & & $018: 1-22: 0$ & $864.3 / 290$ \\
\hline & $018: 1-16: 1$ & $576.3 / 274$ & GD3 & $018: 1-12: 0$ & $693.0 / 290$ \\
\hline & 018:1-16:0 & $577.3 / 274$ & & 018:1-14:0 & $707.0 / 290$ \\
\hline & 018:1-18:1 & $590.3 / 274$ & & $018: 1-15: 0$ & $714.0 / 290$ \\
\hline & $018: 1-18: 0$ & $591.3 / 274$ & & 018:1-16:1 & $720.0 / 290$ \\
\hline & 018:1-20:0 & $605.3 / 274$ & & $018: 1-16: 0$ & $721.0 / 290$ \\
\hline & 018:1-21:0 & $612.3 / 274$ & & 018:1-17:0 & $728.0 / 290$ \\
\hline & $018: 1-22: 0$ & $619.3 / 274$ & & 018:1-18:1 & $734.0 / 290$ \\
\hline & $018: 1-23: 0$ & $626.3 / 274$ & & $018: 1-18: 0$ & $735.0 / 290$ \\
\hline & $018: 1-24: 0$ & $633.3 / 274$ & & $018: 1-19: 0$ & $742.0 / 290$ \\
\hline & & & & $018: 1-20: 0$ & $749.0 / 290$ \\
\hline & & & & $018: 1-21: 0$ & $756.0 / 290$ \\
\hline & & & & 018:1-22:0 & $763.0 / 290$ \\
\hline & & & & $018: 1-23: 0$ & $770.0 / 290$ \\
\hline & & & & $018: 1-24: 0$ & $777.0 / 290$ \\
\hline & & & & $018: 1-25: 0$ & $784.0 / 290$ \\
\hline
\end{tabular}

matrices. For the determination of exogenous compounds that do not present in intended matrices, the conventional standard cali bration is usually employed to generate calibration curves based on six or more levels of analytes spiked into analyte free matrices. However, for the measurement of endogenous compounds that originally present in the sample biomatrices at significant concen trations, the standard addition calibration has been widely used for the establishment of matrix matched calibration. Commonly, each standard calibration curve is constructed on a set of three or four different concentrations prepared by the addition (including a nil addition) of known amounts of analyte standard into aliquots of a sample to be measured. Recent publications involving the appli cation of standard addition calibration include the quantification of bile acids [34), sialic acids [35), gangliosides [29,36), and other endogenous compounds [37 39] in various biomatrices. In most
Table 3

Comparison of extraction recoveries between the reported method (30) and our protein precipitation procedure $(n \cdot 3)$.

\begin{tabular}{|c|c|c|c|c|}
\hline \multirow[t]{3}{*}{ Species } & \multicolumn{4}{|l|}{ Extraction recovery (\%) } \\
\hline & \multicolumn{2}{|c|}{ Protein precipitation procedure } & \multicolumn{2}{|l|}{ Reported method } \\
\hline & Recovery (mean \pm SD,\%) & $\mathrm{Cl} /(\%)$ & Recovery (mean \pm SD, $\%$ ) & $\mathrm{Cl} /(\%)$ \\
\hline GM2 & $100 \pm 8$ & 7.83 & $66 \pm 6$ & 9.70 \\
\hline GM3 & $94 \pm 7$ & 7.93 & $41 \pm 4$ & 9.12 \\
\hline $\mathrm{CO} 2$ & $106 \pm 9$ & 8.69 & $103 \pm 5$ & 4.46 \\
\hline GD3 & $99 \pm 5$ & 4.98 & $102 \pm 9$ & 923 \\
\hline
\end{tabular}

Note: SD, standard deviation.

of these studies, including determination of gangliosides in milk and buttermilk, three or four points were used to construct the cal ibration curves.

As indicated earlier, one of our objectives for the development of this assay was to screen the ganglioside levels in plasma from patients with GM3 synthase deficiency during clinical treatments. We chose three level standard addition considering that these patients are mostly children or even infants and could provide only small amounts of plasma for the study. As shown in Fig. 2, the exemplified calibration curves had $\mathrm{R}^{2}$ values in the range of 0.9998 to 1 for all four ganglioside species, demonstrating a good linear relationship between the analyte response and concentra tion. For the method validation, we prepared known concentration samples by spiking ganglioside standards into aliquots of analyte free plasma from GSD patients. Analysis of such known samples has shown that our assay employing the three level standard addi tion offered satisfactory precision and accuracy for the measure ment of all the four ganglioside species in plasma, which is detailed below.

\section{Precisionand accuracy}

The precision and accuracy for both intra and inter assays were assessed by measuring analyte free plasma samples spiked with the ganglioside standards in triplicate. As shown in Table 4, the coefficient of variation (CV) for intra and inter assays of all measured ganglioside species was within a range from 0.4 to $6 \%$ with a relative error of less than $9 \%$ Conclusively, the precision

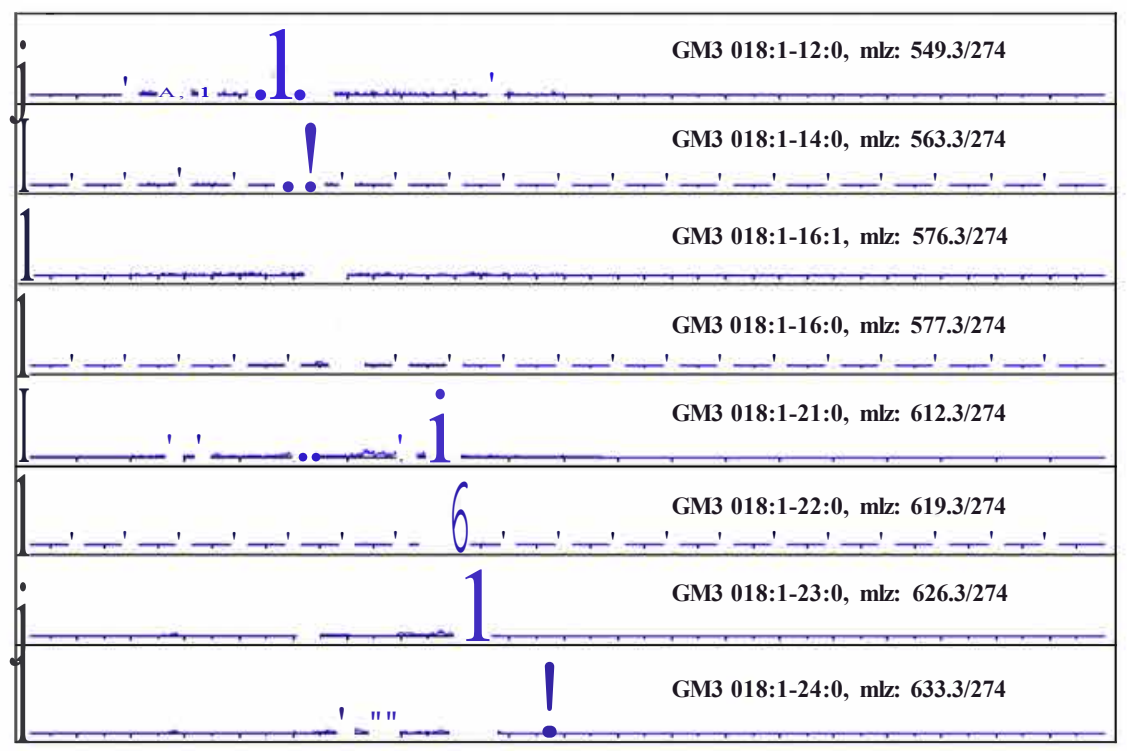

Fig.5. Representative chromatograms for major components of GMB in the plasma extract from a healthy subject. 
Table 4

Intra- and inter-assay precision and accuracy for the measurement of gangliosides spiked in analyte-free human plasma from GSD patients ( $n=3$ ).

\begin{tabular}{|c|c|c|c|c|c|c|c|}
\hline \multirow[t]{2}{*}{ Species } & \multirow[t]{2}{*}{ Spiked concentrations $(\mu \mathrm{g} / \mathrm{ml})$} & \multicolumn{3}{|l|}{ Intra-assay } & \multicolumn{3}{|l|}{ Inter-assay } \\
\hline & & Measured $($ mean $\pm \mathrm{SD}, \mu \mathrm{g} / \mathrm{ml})$ & Precision (CV \%) & Accuracy (RE \%) & Measured $($ mean $\pm \mathrm{SD}, \mu \mathrm{g} / \mathrm{ml})$ & Precision (CV \%) & Accuracy (RE \%) \\
\hline GM2 & 1.00 & $0.99 \pm 0.025$ & 2.52 & -0.60 & $1.04 \pm 0.059$ & 5.67 & 4.45 \\
\hline GM3 & 4.53 & $4.45 \pm 0.019$ & 0.42 & -1.81 & $4.60 \pm 0.156$ & 3.40 & 1.50 \\
\hline GD2 & 0.04 & $0.05 \pm 0.002$ & 3.82 & 8.45 & $0.04 \pm 0.002$ & 3.27 & 7.02 \\
\hline GD3 & 0.67 & $0.69 \pm 0.043$ & 6.13 & 3.82 & $0.70 \pm 0.040$ & 5.75 & 4.35 \\
\hline
\end{tabular}

Note: SD, standard deviation; RE, relative error.

and accuracy of our quantitative method well fulfill the $15 \%$ error and variation tolerance as required by the FDA guidelines for bio analytical method validation [33].

\section{Stability}

The pre and post extraction stabilities of gangliosides in plasma under various storage conditions were evaluated via the analysis of samples prepared from the analyte free plasma spiked with the gangliosides after undergoing the studied storage condi tions, and the results are listed in Table 5 . The stability of $4 \mathrm{~h}$ pre extraction storage at room temperature was assessed by spik ing gangliosides into the thawed analyte free plasma, letting the spiked samples stand at room temperature for $4 \mathrm{~h}$, and then ana lyzing the samples via LC/MS immediately following the extraction procedure. The stability of $8 \mathrm{~h}$ post extraction storage at room temperature was evaluated by spiking gangliosides into analyte free plasma, extracting the spiked samples, letting the extracts stand at room temperature for $8 \mathrm{~h}$, and then injecting them into LC/MS for analysis. The measured stability values for the four gan glioside species range from 86 to $110 \%$ under three different stor age conditions: 1 month pre extraction at $20^{\circ} \mathrm{C}, 4 \mathrm{~h}$ pre extraction at room temperature, and $8 \mathrm{~h}$ post extraction at room temperature. Apparently, the gangliosides were stable in the plasma at the stages of frozen storage, sample treatment, and analysis.

\section{Matrix effect}

The matrix effect for MS detection of gangliosides was assessed through comparable analysis of analyte free plasma extracts spiked with ganglioside standards and the pure solvent spiked with such standards at the same contractions in triplicate. It was found that the matrix impurities substantially suppressed the gan glioside signals, and the LC/MS/MS peak areas from the plasma extracts were only $61.3,36.0,68.3$, and $49.0 \%$ in comparison with the pure solvent for ganglioside GM2, GM3, GD2, and GD3, respec tively. By using the standard addition calibration, the matrix effect had practically no influence on the measurement because the same matrix was used for the calibrators and the relevant samples,

Table 5

Stabilities of gangliosides in human plasma under various storage conditions $(n=3)$.

\begin{tabular}{lcccc}
\hline Stored conditions & \multicolumn{4}{l}{ Recovery (mean \pm SD, \%) } \\
\cline { 2 - 5 } & GM2 & GM3 & GD2 & GD3 \\
\hline $\begin{array}{l}\text { 1-month pre-extraction storage at } \\
-20{ }^{\circ} \mathrm{C}\end{array}$ & $104 \pm 9$ & $90.5 \pm 8$ & $84.2 \pm 5$ & $86.5 \pm 4$ \\
$\begin{array}{l}\text { 4-h pre-extraction storage at room } \\
\text { temperature }\end{array}$ & $96.3 \pm 7$ & $98.6 \pm 2$ & $86.2 \pm 7$ & $88.8 \pm 6$ \\
$\begin{array}{c}\text { 8-h post-extraction storage at } \\
\text { room temperature }\end{array}$ & $101 \pm 3$ & $106 \pm 1$ & $106 \pm 5$ & $110 \pm 6$ \\
\hline
\end{tabular}

Note: SD, standard deviation.
Table 6

Ganglioside concentrations in plasma samples from different specimens measured by our assay.

\begin{tabular}{|c|c|c|c|c|c|}
\hline \multirow[t]{2}{*}{ Subjects } & \multirow[t]{2}{*}{ Total } & \multicolumn{4}{|c|}{ Average levels } \\
\hline & & $\begin{array}{l}\mathrm{GM} 2 \text { (mean } \\
\mathrm{SD}, \mu \mathrm{g} / \mathrm{ml})\end{array}$ & $\begin{array}{l}\mathrm{GM} 3(\text { mean } \pm \\
\mathrm{SD}, \mu \mathrm{g} / \mathrm{ml})\end{array}$ & $\begin{array}{l}\mathrm{GD} 2(\text { mean } \pm \\
\mathrm{SD}, \mu \mathrm{g} / \mathrm{ml})\end{array}$ & $\begin{array}{l}\text { GD3 (mean } \pm \\
\mathrm{SD}, \mu \mathrm{g} / \mathrm{ml})\end{array}$ \\
\hline Normal adults & s 20 & $2.37 \pm 0.79$ & $9.72 \pm 3.68$ & $0.01 \pm 0.01$ & $1.80 \pm 0.64$ \\
\hline GSD patients & 6 & NM & NM & NM & NM \\
\hline
\end{tabular}

Note: SD, standard deviation; NM, not measurable.

which was proven by the high linearity of calibration, precision, and accuracy.

\section{Method application}

The validated LC/MS/MS assay was successfully applied to determine ganglioside concentrations in human plasma from dif ferent specimens, including 20 normal human subjects and 6 GSD patients. As shown in Table 6, the averaged ganglioside levels in the plasma samples from 20 normal human subjects (12 male and 8 female) were $2.37,9.72,0.01$, and $1.80 \mu \mathrm{g} / \mathrm{ml}$ for $\mathrm{GM} 2$, GM3, GD2, and GD3, respectively. In contrast, the analyte free plasma from 6 patients with GSD had no gangliosides presented at a measurable level, which was consistent with the pathological manifestation of the neurodegenerative disorder. The averaged GM3 concentration in plasma samples from 8 healthy human sub jects determined by a published LC/MS method [40] was $7.2 \mu \mathrm{g} / \mathrm{ml}$, which was quite comparable to our result $(9.72 \mu \mathrm{g} / \mathrm{ml})$.

\section{Conclusion}

This article has detailed the development and validation of a sensitive LC/MS/MS method for the determination of gangliosides GM2, GM3, GD2, and GD3 in human plasma. This method used a simple protein precipitation procedure for rapid extraction of the gangliosides from the matrix, UPLC for high resolution chromato graphic separation, and multiple MRM transitions for sensitive and specific MS detection that had been successfully applied to determine the level of gangliosides in plasma from normal human subjects. Considering the quickness, sensitivity, and specificity of this assay, we believe that it is also applicable to other potential biomatrices with some appropriate modifications.

\section{References}

[1] R.K. Yu, Y. Nakatani, M. Yanagisawa, The role of glycosphingolipid metabolism in the developing brain, J. Lipid Res. 50 (2009) S440-S445.

[2] L. Svennerholm, The gangliosides, J. Lipid Res. 5 (1964) 145-155.

[3] R.K. Yu, Y. Tsai, T. Ariga, Functional roles of gangliosides in neurodevelopment: an overview of recent advances, Neurochem. Res. 37 (2012) 1230-1244.

[4] K. Furukawa, Y. Ohmi, Y. Ohkawa, N. Tokuda, Y. Kondo, O. Tajima, K. Furukawa, Regulatory mechanisms of nervous systems with glycosphingolipids, Neurochem. Res. 36 (2011) 1578-1586. 
[5] S. Hakomori, K. Handa, K. Iwabuchi, S. Yamamura, A. Prinetti, New insights in glycosphingolipid function: "Glycosignaling domain", a cell surface assembly of glycosphingolipids with signal transducer molecules, involved in cell adhesion coupled with signaling, Glycobiology 8 (1998) xi-xix.

[6] C.B. Zeller, R.B. Marchase, Gangliosides as modulators of cell function, Am. J. Physiol. 262 (1992) C1341-C1355.

[7] T. Kolter, F. Winau, U.E. Schaible, M. Leippe, K. Sandhoff, Lipid-binding proteins in membrane digestion, antigen presentation, and antimicrobial defense, J. Biol. Chem. 280 (2005) 41125-41128.

[8] T. Ariga, W.D. Jarvis, R.K. Yu, Role of sphingolipid-mediated cell death in neurodegenerative diseases, J. Lipid Res. 39 (1998) 1-16.

[9] R.G.W. Anderson, The caveolae membrane system, Annu. Rev. Biochem. 67 (1998) 199-225.

[10] K. Simons, R. Ehehalt, Cholesterol, lipid rafts, and disease, J. Clin. Invest. 110 (2002) 597-603.

[11] M.A. Simpson, H. Cross, C. Proukakis, D.A. Priestman, D.C. Neville, G. Reinkensmeier, et al., Infantile-onset symptomatic epilepsy syndrome caused by a homozygous loss-of-function mutation of GM3 synthase, Nat. Genet. 36 (2004) 1225-1229.

[12] F. Farukhi, C. Dakkouri, H. Wang, M. Wiztnitzer, E. Traboulsi, Etiology of vision loss in ganglioside GM3 synthase deficiency, Ophthalmic Genet. 27 (2006) 8991.

[13] Y. Kacher, A.H. Futerman, Genetic diseases of sphingolipid metabolism: pathological mechanisms and therapeutic options, FEBS Lett. 580 (2006) 5510-5517.

[14] D.J. Mahuran, Biochemical consequences of mutations causing the GM2 gangliosidoses, Biochim. Biophys. Acta 1455 (1999) 105-138.

[15] G.H.B. Maegawa, T. Stockley, M. Tropak, B. Banwell, S. Blaser, F. Kok, R. Giugliani, D. Mahuran, J.T. Clarke, The natural history of juvenile or subacute GM2 gangliosidosis: 21 new cases and literature review of 134 previously reported, Pediatrics 118 (2006) e1550-e1562.

[16] T. Itakura, A. Kuroki, Y. Ishibashi, D. Tsuji, E. Kawashita, Y. Higashine, H. Sakuraba, S. Yamanaka, K. Itoh, Inefficiency in GM2 ganglioside elimination by human lysosomal $\beta$-hexosaminidase $\beta$-subunit gene transfer to fibroblastic cell line derived from Sandhoff disease model mice, Biol. Pharm. Bull. 29 (2006) 1564-1569.

[17] D.R. Martin, N.R. Cox, N.E. Morrison, D.M. Kennamer, S.L. Peck, A.N. Dodson, et al., Mutation of the GM2 activator protein in a feline model of GM2 gangliosidosis, Acta Neuropathol. 110 (2005) 443-450.

[18] P. Cordeiro, P. Hechtman, F. Kaplan, The GM2 gangliosidoses databases: allelic variation at the HEXA, HEXB, and GM2A gene loci, Genet. Med. 2 (2000) 319327.

[19] E.A. Fazzini, The Effect of Gangliosides on a Neurotoxin (MPTP) Induced Model of Parkinson's Disease in Mice, Boston University, Boston, 1989. p. 175.

[20] E. Di Pasquale, J. Fantini, H. Chahinian, M. Maresca, N. Taïeb, N. Yahi, Altered ion channel formation by the Parkinson's-disease-linked E46K mutant of $\alpha$ synuclein is corrected by GM3 but not by GM1 gangliosides, J. Mol. Biol. 397 (2010) 202-218.

[21] T. Ariga, M.P. McDonald, R.K. Yu, Role of ganglioside metabolism in the pathogenesis of Alzheimer's disease-a review, J. Lipid Res. 49 (2008) 11571175.

[22] F. Majer, L. Trnka, L. Vítek, M. Jirkovská, Z. Marecek, F. Smíd, Estrogen-induced cholestasis results in a dramatic increase of $b$-series gangliosides in the rat liver, Biomed. Chromatogr. 21 (2007) 446-450.
[23] B. Kniep, P.F. Muehlradt, Immunochemical detection of glycosphingolipids on thin-layer chromatograms, Anal. Biochem. 188 (1990) 5-8.

[24] E.M. Kaye, M.D. Ullman, E.H. Kolodny, W. Krivit, J.C. Rischert, Possible use of CSF glycosphingolipids for the diagnosis and therapeutic monitoring of lysosomal storage diseases, Neurology 42 (1992) 2290-2294.

[25] M.D. Ullman, R.H. McCluer, Quantitative analysis of brain gangliosides by high performance liquid chromatography of their perbenzoyl derivatives, J. Lipid Res. 26 (1985) 501-506.

[26] J. Kuei, G.R. Her, V.N. Reinhold, Supercritical fluid chromatography of glycosphingolipids, Anal. Biochem. 172 (1988) 228-234.

[27] D. Tsuji, Y. Higashine, K. Matsuoka, H. Sakuraba, K. Itoh, Therapeutic evaluation of GM2 gangliosidoses by ELISA using anti-GM2 ganglioside antibodies, Clin. Chim. Acta 378 (2007) 38-41.

[28] J. Gu, C.J. Tifft, S.J. Soldin, Simultaneous quantification of GM1 and GM2 gangliosides by isotope dilution tandem mass spectrometry, Clin. Biochem. 41 (2008) 413-417.

[29] L.K. Sørensen, A liquid chromatography/tandem mass spectrometric approach for the determination of gangliosides GD3 and GM3 in bovine milk and infant formulae, Rapid Commun. Mass Spectrom. 20 (2006) 3625-3633.

[30] L. Svennerholm, P. Fredman, A procedure for the quantitative isolation of brain gangliosides, Biochim. Biophys. Acta 617 (1980) 97-109.

[31] B. Fong, C. Norris, E. Lowe, P. McJarrow, Liquid chromatography-highresolution mass spectrometry for quantitative analysis of gangliosides, Lipids 44 (2009) 867-874.

[32] K. Ikeda, T. Shimizu, R. Taguchi, Targeted analysis of ganglioside and sulfatide molecular species by LC/ESI-MS/MS with theoretically expanded multiple reaction monitoring, J. Lipid Res. 49 (2008) 2678-2689.

[33] U.S. Food and Drug Administration, Guidance for Industry: Bioanalytical Method Validation, U.S. Department of Health and Human Services, FDA, Center for Drug Evaluation and Research, Rockville, MD, 2001.

[34] X. Cai, Y. Liu, X. Zhou, U. Navaneethan, B. Shen, B. Guo, An LC-ESI-MS method for the quantitative analysis of bile acids composition in fecal materials, Biomed. Chromatogr. 26 (2012) 101-108.

[35] S.F. Fernando, B.W. Woonton, Quantitation of $N$-acetylneuraminic (sialic) acid in bovine glycomacropeptide (GMP), J. Food Compos. Anal. 23 (2010) 359366.

[36] B. Fong, C. Norris, P. McJarrow, Liquid chromatography-high-resolution electrostatic ion-trap mass spectrometric analysis of GD3 ganglioside in dairy products, Int. Dairy J. 21 (2011) 42-47.

[37] S. McSheehy, L. Yang, R. Sturgeon, Z. Mester, Determination of methionine and selenomethionine in selenium-enriched yeast by species-specific isotope dilution with liquid chromatography-mass spectrometry and inductively coupled plasma mass spectrometry detection, Anal. Chem. 77 (2005) 344-349.

[38] A. Ćirić, H. Prosen, M. Jelikić-Stankov, P. Đurdević, Evaluation of matrix effect in determination of some bioflavonoids in food samples by LC-MS/MS method, Talanta 99 (2012) 780-790.

[39] B. Preinerstorfer, S. Schiesel, M. Lämmerhofer, W. Lindner, Metabolic profiling of intracellular metabolites in fermentation broths from $\beta$-lactam antibiotics production by liquid chromatography-tandem mass spectrometry methods, J. Chromatogr. A 1217 (2010) 312-328.

[40] H.H. Bui, J.K. Leohr, M. Kuo, Analysis of sphingolipids in extracted human plasma using liquid chromatography electrospray ionization tandem mass spectrometry, Anal. Biochem. 423 (2012) 187-194. 